\title{
A poly(ADP-ribose) synthetase inhibitor, benzamide protects smooth muscle cells but not endothelium against ischemia/reperfusion injury in isolated guinea-pig heart
}

\author{
Andrzej Jakubowski ${ }^{\bowtie}$ and Magdalena Lomnicka \\ Department of Experimental Pharmacology, Chair of Pharmacology, Medical College of the Jagiellonian \\ University, Kraków, Poland
}

Received: 12 April, 2006; revised: 26 February, 2007; accepted: 08 March, 2007

available on-line: 20 March, 2007

\begin{abstract}
Activation of the nuclear enzyme poly(ADP-ribose) synthethase (PARS) is important in the cellular response to oxidative stress. During ischemia and reperfusion (I/R) increased free radical production leads to DNA breakage that stimulates PARS which in turn results in an energy-consuming metabolic cycle and initiation of the apoptotic process. Previous studies have reported that PARS inhibition confers protection in various models of $I / R$-induced cardiovascular damage. The purpose of this study was to determine the role of PARS inhibition in I/R-induced injury of smooth muscle cells and endothelium in the coronary circulation of the isolated guinea-pig heart. Control hearts and those treated with a PARS inhibitor - benzamide $\left(100 \mu \mathrm{mol} \mathrm{L}{ }^{-1}\right)$, were subjected to $30 \mathrm{~min}$ of subglobal ischemia and subsequent reperfusion $(90 \mathrm{~min})$. To analyze the functional integrity of smooth muscle cells and endothelium, one-minute intracoronary infusions of endothelium-independent (sodium nitroprusside, NaNP; $3 \mu \mathrm{mol} \mathrm{L}^{-1}$ ) and endothelium-dependent (substance $\mathrm{P}$, SP; $10 \mathrm{nmol} \mathrm{L}^{-1}$ ) vasodilators were used before ischemia and at the reperfusion time. The degree of the injury of coronary smooth muscle and endothelial cells induced by I/ $R$ was estimated in terms of diminished vasodilator responses to NaNP (at 55 min and $85 \mathrm{~min}$ of reperfusion) and to SP (at $70 \mathrm{~min}$ of reperfusion), respectively, and expressed as the percentage of preischemic response. $I / R$ reduced vasorelaxant responses to both vasodilators by half (to $54.1 \pm 5.1 \%$ and to $53.6 \pm 4.9 \%$ of preischemic value for NaNP at $55 \mathrm{~min}$ and $85 \mathrm{~min}$ of reperfusion, respectively and to $45.9 \pm 6.5 \%$ for SP at $70 \mathrm{~min}$ of reperfusion). PARS inhibition provided complete restoration of vasorelaxation induced by NaNP $(107.6 \pm 13.3 \%$ and $104 \pm 14.4 \%$ of preischemic response at the two time points of reperfusion, respectively). However, there was no effect on the SP-induced response $(48+12.1 \%$ of preischemic response). We conclude that pharmacological PARS inhibition with benzamide protects coronary smooth muscle cells but not endothelium against I/R-induced reperfusion injury in the coronary circulation of the guinea-pig heart.
\end{abstract}

Keywords: PARS, I/R-induced reperfusion injury, coronary vessels, endothelium, smooth muscle cells

\section{INTRODUCTION}

Poly(ADP-ribose) synthetase (PARS) is one of the most abundant enzymes in the eukaryotic cell. Its main role is to maintain genomic integrity by aiding of damaged DNA. PARS catalyzes the cleavage of $\mathrm{NAD}^{+}$into nicotinamide and ADP-ribose and uses the latter for the synthesis of branched nucleic acid-like polymers - poly(ADP-ribose) (de Murcia et al., 1994; Lindahl et al., 1995). PARS activity play role in the regulation of cell replication and differentiation (Tanuma et al., 1978; Bakondi et al., 2002). Activated PARS utilizes cellular $\mathrm{NAD}^{+}$(Jacobson et al., 1979) so the level of cellular ATP declines dra-

Author for correspondence: Andrzej Jakubowski, Department of Experimental Pharmacology, Chair of Pharmacology, The Jagiellonian University School of Medicine, Grzegórzecka Str. 16, 31-531 Kraków, Poland; e-mail: mfjakubo@cyf-kr.edu.pl

Abbreviations: Ach, acetylcholine; I/R, ischemia-reperfusion; NaNP, sodium nitroprusside; PARS, poly(ADP-ribose) synthetase; SP, substance P. 
matically (Goodwin et al., 1978; Sims et al., 1983) and affects cell integrity. Moreover, low level of $\mathrm{NAD}^{+}$inhibits ATP regeneration and blocks reactivation of oxidized glutathione resulting in a lack of the main defensive mechanism against ischemic injury in the cells. All these changes lead to massive necrosis of cells subjected to ischemia/reperfusion (I/R). It has been shown that $I / R$ stimulates generation of oxygen-derived free radicals (Lefer et al., 1991), which can damage DNA and over-activate PARS. Therefore PARS inhibition at I/R should limit postischemic cell damage. In fact, many studies have shown beneficial effects of PARS inhibition in oxidative stress-related pathologies (Virag, 2005). It was proved that inhibition of PARS activity reduces heart damage in different models of ischemic cardiovascular injury (Thiemermann et al., 1997; Farivar et al., 2005; Nagata et al., 2005). However, most in vitro and in vivo studies focused on postreperfusion damage of myocardial function (Yamazaki et al., 2004). Less is known about the role of PARS in the injury of vascular smooth muscle and endothelial cells (Mehta et al., 1989; Lefer et al., 1991). Current observations are not clear. Virag and Szabo (2002) showed that PARS inhibition with 3aminobenzamide prevented the vasospasm caused by subarachnoid haemorrhage and improved vascular function in diabetes. Improved recovery of endothelial function was shown in pulmonary and splanchnic arteries in rats (Nagata et al., 2005). On the other hand, Szabo group revealed in many studies that inhibition of PARS only partially protected vascular smooth muscle or endothelial cells exposed to various models of oxidative-related injury (Szabo et al., 1996; 2004b; Andrasi et al., 2005). Therefore the aim of the present study was to determine if PARS inhibition with benzamide reduces to the same degree I/R-induced injury of vascular smooth muscle cells and endothelium in the coronary circulation of the isolated guinea-pig heart.

\section{MATERIALS AND METHODS}

Chemicals. Acetylcholine (Ach), substance $\mathrm{P}$ (SP) and sodium nitroprusside (NaNP) were obtained from Sigma Chemical Co. (St. Louis, MO, USA). Benzamide was received as a kind gift from Professor Thiemermann (The William Harvey Research Institute, London, England).

Perfusion of the isolated guinea-pig heart. The method was described in details previously (Chlopicki \& Gryglewski, 1993). Briefly, guinea-pig hearts were inversely perfused through the ascending aorta according to the Langendorff technique (Hugo Sachs Elektronik, HSE) with the Krebs-Henseleit buffer of the following composition $\left(\mathrm{mmol} \mathrm{L}^{-1}\right)$ :
$\mathrm{KCl} 4.7, \mathrm{NaCl} 118, \mathrm{CaCl}_{2} 2.52, \mathrm{MgSO}_{4} 1.64, \mathrm{NaHCO}_{3}$ $24.88, \mathrm{KH}_{2} \mathrm{PO}_{4} 1.18$, glucose 5.55 , sodium pyruvate 2.0, equilibrated with $95 \% \mathrm{O}_{2}+5 \% \mathrm{CO}_{2}$ at $37^{\circ} \mathrm{C}$. The heart was paced at 273 impulses per minute through platinum electrodes inserted to the right atrium. Left ventricular pressure (LVP) was measured using a fluid-filled balloon inserted into the left ventricle and connected to a pressure transducer (Isotec HSE). Heart systolic contractility was calculated from the LVP signal by an analogue differentiation amplifier (DIF module, HSE). Coronary flow was monitored by Narcomatic Electronic Flowmeter (HSE). All parameters were continuously displayed throughout the experiment and then analysed by a dedicated software (PSCF-IGEL, Poland). All experiments were completed in less than three hours.

Experimental protocol. Hearts were equilibrated at the perfusion pressure of $50 \mathrm{~mm} \mathrm{Hg}$ for $10 \mathrm{~min}$ and then the pressure was raised to $60 \mathrm{~mm}$ $\mathrm{Hg}$. The hearts were used for the experiment only if basal coronary flow was higher than $5 \mathrm{ml} \mathrm{min}^{-1}$ and bolus injection of acetylcholine (Ach, 300 pmoles) in-

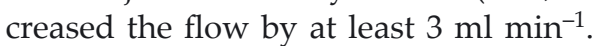

Coronary vessels were tested for endotheliumdependent vasorelaxant responses with one-minute intracoronary infusions of substance P (SP, $10 \mathrm{nmol}$ $\mathrm{L}^{-1}$ ) and for endothelium-independent vasorelaxant responses with sodium nitroprusside (NaNP, $3 \mu \mathrm{mol} \mathrm{L} \mathrm{L}^{-1}$.

Next, the hearts were subjected to $30 \mathrm{~min}$ of subglobal ischemia (90-95\% reduction in coronary flow) followed by a $90 \mathrm{~min}$ reperfusion during which the vasodilator responses were tested again. $\mathrm{NaNP}$ was infused at $55 \mathrm{~min}$ and $85 \mathrm{~min}$ of reperfusion. SP as endothelium-dependent vasodilator was administered only once during reperfusion (at $70 \mathrm{~min}$ ) because its repetitive administration (in time intervals shorter than $15 \mathrm{~min}$ ) leads to a decrease in vasorelaxant responses (tachyphylaxis). The magnitude of all vascular responses was calculated as the area under the curve of coronary flow.

Control hearts were compared with hearts perfused with Krebs buffer containing benzamide $\left(100 \mu \mathrm{mol} \mathrm{L}^{-1}\right)$ from the beginning of the experiment. The time schedule of $\mathrm{I} / \mathrm{R}$ was established on the basis of previous experiments to obtain selective impairment of the response of coronary vessels to vasoactive substances with a relatively small effect on the basal coronary flow and heart contractility. In additional series of experiments the effect of benzamide $\left(100 \mu \mathrm{mol} \mathrm{L}^{-1}\right)$ on basal hemodynamic functions and vasorelaxant responses was checked.

The investigation conforms to the Guide for the Care and Use of Laboratory Animals published by the US National Institutes of Health and the experimental procedure used in the present study 
Table 1. Effect of $30 \mathrm{~min}$ ischemia and $90 \mathrm{~min}$ of reperfusion (I/R) on coronary flow and heart systolic contractility of isolated guinea-pig heart.

Treatment with benzamide $\left(100 \mu \mathrm{mol} \mathrm{L}{ }^{-1}\right)$ did not affect listed parameters significantly $(\mathrm{n}=10)$.

\begin{tabular}{|c|c|c|c|c|c|c|}
\hline \multirow[t]{2}{*}{ Parameter } & \multicolumn{6}{|l|}{ Time point } \\
\hline & Basal & $\begin{array}{l}\text { Treatment with } \\
\text { benzamide }(30 \mathrm{~min})\end{array}$ & $\begin{array}{l}\text { I/R } \\
(45 \mathrm{~min})\end{array}$ & $\begin{array}{l}\mathrm{I} / \mathrm{R} \\
(90 \mathrm{~min})\end{array}$ & $\begin{array}{l}\text { I/R } \\
(45 \text { min })+ \\
\text { Benzamide }\end{array}$ & $\begin{array}{l}\mathrm{I} / \mathrm{R} \\
(90 \mathrm{~min})+ \\
\text { Benzamide }\end{array}$ \\
\hline $\begin{array}{l}\text { Coronary Flow } \\
\left.(\mathrm{ml} \mathrm{min})^{-1}\right)\end{array}$ & $6.12 \pm 0.7$ & $5.75 \pm 0.92$ & $5.63 \pm 0.87$ & $5.85 \pm 0.9$ & $5.81 \pm 1.02$ & $6.03 \pm 0.99$ \\
\hline $\begin{array}{l}\text { Heart systolic contractility } \\
\left(\mathrm{mm} \mathrm{Hg} \mathrm{s}^{-1}\right)\end{array}$ & $1021 \pm 93$ & $949.5 \pm 95$ & $969.9+91$ & $991 \pm 85$ & $1006 \pm 106$ & $998 \pm 103$ \\
\hline
\end{tabular}

was approved by the Jagiellonian University Ethical Committee.

Statistics. Changes in vasodilator responses are shown as the percentage of basal preischemic values. Statistical significance between groups was evaluated by unpaired Student's $t$-test and within the group by paired $t$-test.

\section{RESULTS}

Basal coronary flow was $6.12 \pm 0.78 \mathrm{ml} \mathrm{min}{ }^{-1}$ and heart systolic contractility was $1021 \pm 93 \mathrm{~mm}$ $\mathrm{Hg} \mathrm{s}^{-1}(\mathrm{n}=10)$.

Benzamide at a concentration of $100 \mu \mathrm{mol}$ $\mathrm{L}^{-1}$ did not affect cardiac functions significantly. After a $30 \mathrm{~min}$ perfusion with benzamide, the basal coronary flow and heart systolic contractility were reduced by $6-7 \%$ (Table 1 ). Treatment with benzamide also did not change the vasodilator responses significantly. Vasodilatation caused by substance $\mathrm{P}$ (SP) was slightly higher (from $10 \%$ to $3 \%$ after 30 and $90 \mathrm{~min}$, respectively) and by sodium nitroprusside (NaNP) smaller (from $10 \%$ to $4 \%$ after 30 and $90 \mathrm{~min}$, respectively) in the presence of PARS inhibitor (Fig. 1).

Ischemia and subsequent reperfusion slightly, non-significantly, decreased coronary flow and heart systolic contractility. A thirty-minute ischemia and $45 \mathrm{~min}$ of reperfusion decreased coronary flow by $8 \%$ (ns) and heart systolic contractility by $5 \%$ (ns) as compared to basal values. A similar degree of impairment of coronary flow and heart systolic contractility was observed at the end of the reperfusion. In benzamide-treated hearts these values were almost identical (Table 1).

The effect of $I / R$ on coronary vessel function was much more pronounced. $I / R$ reduced endothelium-independent coronary responses to NaNP approximately by half, i.e. to $54.1 \pm 5.1 \%(P<0.001)$ and to $53.6 \pm 4.9 \%(P<0.001)$ of preischemic values, at 55 $\min$ and $85 \mathrm{~min}$ of reperfusion, respectively. Similarly, the endothelium-dependent vasodilator re-

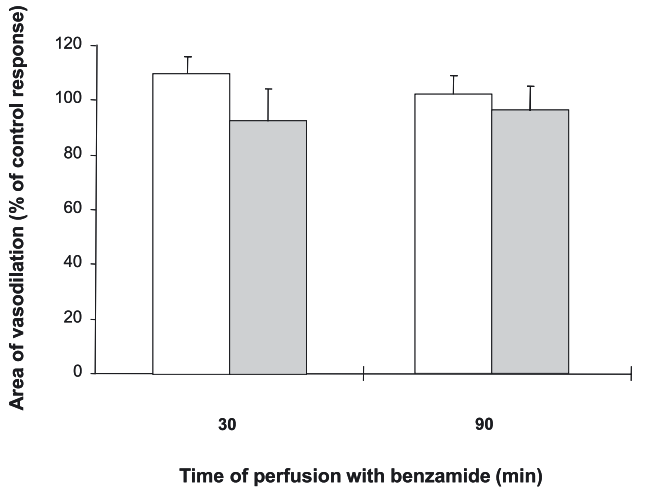

Figure 1. Effects of 90 min perfusion with benzamide $\left(100 \mu \mathrm{mol} \mathrm{L}^{-1}\right)$ on coronary vessel responses to endothelium-dependent (substance $P, S P$ ) and endothelium-independent (sodium nitroprusside, NaNP) vasodilators in isolated perfused guinea-pig hearts.

Data expressed as percentage of control response. Open columns, vasodilatation evoked by SP $\left(10 \mathrm{nmol} \mathrm{L}^{-1}\right)$; filled columns, vasodilatation evoked by $\operatorname{NaNP}\left(3 \mu \mathrm{mol} \mathrm{L} \mathrm{L}^{-1}\right)$, $(n=10)$.

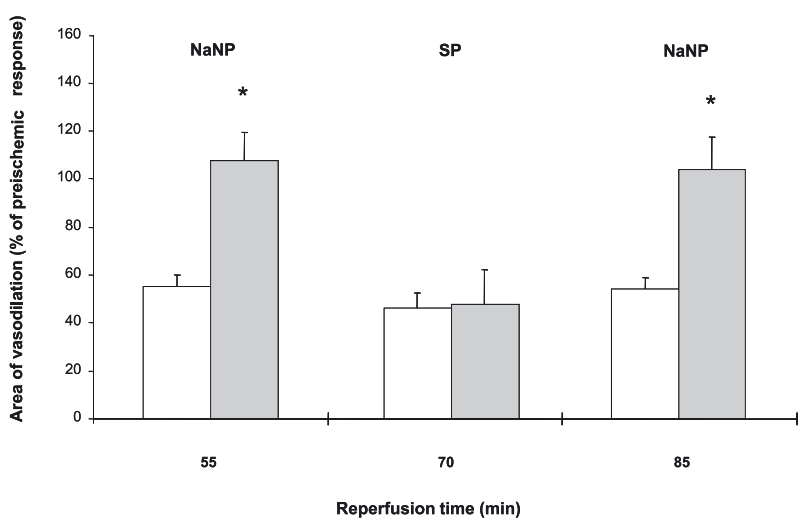

Figure 2. Effects of benzamide $\left(100 \mu \mathrm{mol} \mathrm{L} \mathrm{L}^{-1}\right)$ on coronary vessel responses to endothelium-dependent (sub-

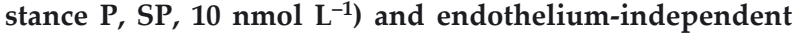
(sodium nitroprusside, NaNP, $3 \mu \mathrm{mol} \mathrm{L}^{-1}$ ) vasodilators in isolated, perfused guinea-pig hearts subjected to $30 \mathrm{~min}$ subglobal ischemia and $\mathbf{9 0} \mathrm{min}$ reperfusion.

Data expressed as percentage of preischemic response. Open columns, control hearts; filled columns, hearts treated with benzamide. $\left({ }^{*} P<0.005\right.$ between groups; $\left.n=10\right)$. 
sponse to SP was depressed to $45.9 \pm 6.5 \%(P<0.001)$ at $70 \mathrm{~min}$ of reperfusion.

PARS inhibition protected the function of smooth muscle but not of the endothelial cells of coronary vessels against I/R-induced reperfusion injury. The suppression of endothelium-independent vascular responses to NaNP was totally reversed in benzamide-treated hearts. In this group, the increase in coronary flow reached $107.6 \pm 13.3 \%$ and $104.0 \pm 14.4 \%$ of preischemic values at 55 and $85 \mathrm{~min}$ of reperfusion, respectively $(P<0.005$ vs non-treated hearts). In contrast, the I/R-induced suppression of endothelium-dependent vasodilator responses to SP remained reduced to $48.0 \pm 12.1 \%$ of the preischemic value (ns vs non-treated group) (Fig. 2).

\section{DISCUSSION}

Although numerous studies describe the role of PARS activation in cell injury, only few investigated the effects of PARS activation in coronary circulation (Gilad et al., 1997).

In the present study we demonstrated that benzamide, a well known PARS inhibitor which is three times more potent than the widely used 3-aminobenzamide, protected smooth muscle but not endothelial cells against I/R-induced injury of coronary vessels in the isolated guinea-pig heart. Inhibition of PARS activity did not affect significantly basal vascular tone or heart contractility. This is consistent with the PARS mode of action where at normal conditions the activity of this enzyme is rather low. However, it has been shown that DNA damage that occurs even after $15 \mathrm{~min}$ of ischemia and subsequent reperfusion increases PARS activity up to 500 times (D'Amours et al., 1999; Virag \& Szabo, 2002). This results in a dramatic increase in ATP consumption and impairment of mitochondrial respiration leading to severe cell damage. PARS activation in cultured endothelial cells in response to oxidative stress was described for the first time by Junod (Junod et al., 1989). Additionally, it was shown that at the time of I/R smooth muscle and endothelial cells produce free radicals causing strong oxidative damage (Virag \& Szabo, 2002). Our experiments showed that $I / R$ led to significant impairment of coronary responses to both endothelium-dependent (SP) and endothelium-independent (NaNP) vasodilators. Because the over-activation of PARS has been shown in isolated heart models (Szabados et al., 2000; Virag \& Szabo, 2002), the use of benzamide should provide reasonable protection of the examined vascular bed. In fact, in our hands, benzamide totally reversed the damage of smooth muscle cells but failed to protect endothelial cells. Our observations are in accordance with the studies by Szabo (Szabo et al., 2004a; 2004b) who showed that profound endothelial dysfunction was only partially reversed by PARS inhibition while vasodilator responses of smooth muscle cells were totally restored. On the other hand, many authors showed complete or at least significant protection also of endothelial cells by chronic or acute PARS inhibition in different vascular beds (Soriano et al., 2001; Szabo et al., 2002; Benko et al., 2004).

This discrepancy shows that the effects of PARS inhibition are difficult to predict and strongly depend on the experimental model used, animal species as well as the inhibitor. Weaker or slower recovery of endothelial function after PARS inhibition (Szabo et al., 1998b; 1998a) indicates that the coronary endothelium is more vulnerable to $\mathrm{I} / \mathrm{R}$-induced injury than other cells (Szabo et al., 2002; 2004b; Pacher et al., 2004). Indeed, Mizuno et al. (1997) demonstrated that after normothermic I/R-induced injury of pig heart, myocardial and endothelial function could be diversified: although the myocardial function showed a full recovery, the endothelial function remained impaired. Sack and coworkers (1997) showed, in human transplant biopsy specimens, that whereas myocyte integrity recovered within $60 \mathrm{~min}$ of reperfusion, regeneration of the endothelium lasted for up to a week.

Another possible explanation of the weaker protective effect of PARS inhibition in endothelial cells is only partial participation of PARS in the I/ R-induced injury of these cells. Indeed, ATP level may not be the only one factor responsible for the impairment of endothelial-dependent response in reperfusion period. It was shown that PARS activation contributed to the expression of adhesive molecules like P-selectin and ICAM-1 in hearts subjected to global $\mathrm{I} / \mathrm{R}$, resulting in neutrophil activation and recruitment into the jeopardized tissue (Jerome et al., 1993; Weyrich et al., 1993; Gilad et al., 1997), which is one of the crucial events for I/R injury. Inhibition of PARS activity in blood-perfused models may additionally prevent the critical neutrophil-endothelium interaction, which in turn leads to a stronger protection of these cells, while in our leukocyte-free model, this component of the beneficial effects was eliminated.

We did not study here the exact mechanisms of the beneficial role of PARS inhibition in the I/Rinduced injury of the coronary vascular bed. However, the role of PARS over-activation in disruption of general cellular energetics is well established.

In summary, we showed that a PARS inhibitor - benzamide provided significant protection of smooth muscle but not of endothelial cells against $\mathrm{I} / \mathrm{R}$-induced injury in the coronary circulation of the isolated guinea-pig heart. Further studies are necessary to explain the mechanism of this phenomenon, and its relation to PARS inhibition. 


\section{REFERENCES}

Andrasi TB, Blazovics A, Szabo G, Vahl CF, Hagl S (2005) Poly(ADP-ribose) polymerase inhibitor PJ-34 reduces mesenteric vascular injury induced by experimental cardiopulmonary bypass with cardiac arrest. Am J Physiol Heart Circ Physiol 288: H2972-H2978.

Bakondi E, Bai P, Szabo EE, Hunyadi J, Gergely P, Szabo C, Virag L (2002) Detection of poly(ADP-ribose) polymerase activation in oxidatively stressed cells and tissues using biotinylated NAD substrate. J Histochem Cytochem 50: 91-98.

Benko R, Pacher P, Vaslin A, Kollai M, Szabo C (2004) Restoration of the endothelial function in the aortic rings of apolipoprotein E deficient mice by pharmacological inhibition of the nuclear enzyme poly(ADP-ribose) polymerase. Life Sci 75: 1255-1261.

Chlopicki S, Gryglewski RJ (1993) Nitric oxide is a major mediator in reactive hyperaemia evoked by a brief coronary occlusion in the guinea pig heart. Eur J Pharmacol 241: 117-120.

D'Amours D, Desnoyers S, D'Silva I, Poirier GG (1999) Poly(ADP-ribosyl)ation reactions in the regulation of nuclear functions. Biochem J 342 (Pt 2): 249-268.

de Murcia G, Schreiber V, Molinete M, Saulier B, Poch O, Masson M, Niedergang C, Menissier de MJ (1994) Structure and function of poly(ADP-ribose) polymerase. Mol Cell Biochem 138: 15-24.

Farivar AS, McCourtie AS, Kinnon-Patterson BC, Woolley SM, Barnes AD, Chen M, Jagtap P, Szabo C, Salerno CT, Mulligan MS (2005) Poly (ADP) ribose polymerase inhibition improves rat cardiac allograft survival. Ann Thorac Surg 80: 950-956.

Gilad E, Zingarelli B, Salzman AL, Szabo C (1997) Protection by inhibition of poly (ADP-ribose) synthetase against oxidant injury in cardiac myoblasts in vitro. $J$ Mol Cell Cardiol 29: 2585-2597.

Goodwin PM, Lewis PJ, Davies MI, Skidmore CJ, Shall S (1978) The effect of gamma radiation and neocarzinostatin on NAD and ATP levels in mouse leukaemia cells. Biochim Biophys Acta 543: 576-582.

Jacobson EL, Lange RA, Jacobson MK (1979) Pyridine nucleotide synthesis in 3T3 cells. J Cell Physiol 99: 417425.

Jerome SN, Smith CW, Korthuis RJ (1993) CD18-dependent adherence reactions play an important role in the development of the no-reflow phenomenon. Am J Physiol 264: H479-H483.

Junod AF, Jornot L, Petersen H (1989) Differential effects of hyperoxia and hydrogen peroxide on DNA damage, polyadenosine diphosphate-ribose polymerase activity, and nicotinamide adenine dinucleotide and adenosine triphosphate contents in cultured endothelial cells and fibroblasts. J Cell Physiol 140: 177-185.

Lefer AM, Tsao PS, Lefer DJ, Ma XL (1991) Role of endothelial dysfunction in the pathogenesis of reperfusion injury after myocardial ischemia. FASEB $J$ 5: 2029-2034.

Lindahl T, Satoh MS, Poirier GG, Klungland A (1995) Post-translational modification of poly(ADP-ribose) polymerase induced by DNA strand breaks. Trends Biochem Sci 20: 405-411.

Mehta JL, Nichols WW, Donnelly WH, Lawson DL, Thompson L, terRiet M, Saldeen TG (1989) Protection by superoxide dismutase from myocardial dysfunction and attenuation of vasodilator reserve after coronary occlusion and reperfusion in dog. Circ Res 65: 12831295.
Mizuno A, Baretti R, Buckberg GD, Young HH, VintenJohansen J, Ma XL, Ignarro LJ (1997) Endothelial stunning and myocyte recovery after reperfusion of jeopardized muscle: a role of L-arginine blood cardioplegia. J Thorac Cardiovasc Surg 113: 379-389.

Nagata H, Horiguchi T, Enzan K, Nishikawa T, Suzuki K (2005) Inhibition of poly (ADP-ribose) synthetase improves pulmonary arterial endothelium-dependent relaxation after ischemic-reperfusion injury of splanchnic artery in rats. Anesth Analg 101: 1799-1804.

Pacher P, Vaslin A, Benko R, Mabley JG, Liaudet L, Hasko G, Marton A, Batkai S, Kollai M, Szabo C (2004) A new, potent poly(ADP-ribose) polymerase inhibitor improves cardiac and vascular dysfunction associated with advanced aging. J Pharmacol Exp Ther 311: 485491.

Sack FU, Lange R, Mehmanesh H, Amman K, Schnabel P, Zimmermann R, Dengler T, Otto HF, Hagl S (1997) Transferral of extrathoracic donor neoplasm by the cardiac allograft. J Heart Lung Transplant 16: 298-301.

Sims JL, Berger SJ, Berger NA (1983) Poly(ADP-ribose) polymerase inhibitors preserve nicotinamide adenine dinucleotide and adenosine 5'-triphosphate pools in DNA-damaged cells: mechanism of stimulation of unscheduled DNA synthesis. Biochemistry 22: 5188-5194.

Soriano FG, Pacher P, Mabley J, Liaudet L, Szabo C (2001) Rapid reversal of the diabetic endothelial dysfunction by pharmacological inhibition of poly(ADP-ribose) polymerase. Circ Res 89: 684-691.

Szabados E, Literati-Nagy P, Farkas B, Sumegi B (2000) BGP-15, a nicotinic amidoxime derivate protecting heart from ischemia reperfusion injury through modulation of poly(ADP-ribose) polymerase. Biochem Pharmacol 59: 937-945.

Szabo C, Zingarelli B, Salzman AL (1996) Role of polyADP ribosyltransferase activation in the vascular contractile and energetic failure elicited by exogenous and endogenous nitric oxide and peroxynitrite. Circ Res 78: 1051-1063.

Szabo G, Bahrle S, Batkai S, Stumpf N, Dengler TJ, Zimmermann R, Vahl CF, Hagl S (1998a) L-Arginine: effect on reperfusion injury after heart transplantation. World J Surg 22: 791-797.

Szabo G, Fazekas L, Bahrle S, MacDonald D, Stumpf N, Vahl CF, Hagl S (1998b) Endothelin-A and -B antagonists protect myocardial and endothelial function after ischemia/reperfusion in a rat heart transplantation model. Cardiovasc Res 39: 683-690.

Szabo G, Bahrle S, Stumpf N, Sonnenberg K, Szabo EE, Pacher P, Csont T, Schulz R, Dengler TJ, Liaudet L, Jagtap PG, Southan GJ, Vahl CF, Hagl S, Szabo C (2002) Poly(ADP-Ribose) polymerase inhibition reduces reperfusion injury after heart transplantation. Circ Res 90: 100-106.

Szabo G, Liaudet L, Hagl S, Szabo C (2004a) Poly(ADP-ribose) polymerase activation in the reperfused myocardium. Cardiovasc Res 61: 471-480.

Szabo G, Soos P, Bahrle S, Zsengeller Z, Flechtenmacher C, Hagl S, Szabo C (2004b) Role of poly(ADP-ribose) polymerase activation in the pathogenesis of cardiopulmonary dysfunction in a canine model of cardiopulmonary bypass. Eur J Cardiothorac Surg 25: 825-832.

Tanuma SI, Enomoto T, Yamada MA (1978) Changes in the level of poly ADP-ribosylation during a cell cycle. Exp Cell Res 117: 421-430.

Thiemermann C, Bowes J, Myint FP, Vane JR (1997) Inhibition of the activity of poly(ADP ribose) synthetase reduces ischemia-reperfusion injury in the heart and skeletal muscle. Proc Natl Acad Sci USA 94: 679-683. 
Virag L (2005) Structure and function of poly(ADP-ribose) polymerase-1: role in oxidative stress-related pathologies. Curr Vasc Pharmacol 3: 209-214.

Virag L, Szabo C (2002) The therapeutic potential of poly(ADP-ribose) polymerase inhibitors. Pharmacol Rev 54: 375-429.

Weyrich AS, Ma XY, Lefer DJ, Albertine KH, Lefer AM (1993) In vivo neutralization of P-selectin protects feline heart and endothelium in myocardial ischemia and reperfusion injury. J Clin Invest 91: 2620-2629.

Yamazaki K, Miwa S, Ueda K, Tanaka S, Toyokuni S, Unimonh O, Nishimura K, Komeda M (2004) Prevention of myocardial reperfusion injury by poly(ADP-ribose) synthetase inhibitor, 3-aminobenzamide, in cardioplegic solution: in vitro study of isolated rat heart model. Eur J Cardiothorac Surg 26: 270-275. 